\title{
Correlations Expression PTEN and Expression IGFR with Expression Ki-67 and The Grading Histopathology of Carcinoma Mammae Invasive
}

\author{
Intan, $\mathrm{SA}^{1}$, Setiawati, $\mathrm{Y}^{2}$, Yenita ${ }^{3}$, Abdiana $^{4}$ \\ \{shintaayuintan@med.unand.ac.id ${ }^{1}$, Yessyamri@gmail.com ${ }^{2}$, yenita@med.unand.ac.id ${ }^{3}$, \\ abdiana.fk.unand@gmail.com ${ }^{4}$ \}
Anatomical Pathology Department of Medical Faculty, Andalas University. Jl. Perintis Kemerdekaan No. 94, Padang 25127, West Sumatra, Indonesia ${ }^{1,2,3}$
Public Health Department of Medical Faculty, Andalas University. Jl. Perintis Kemerdekaan No. 94, Padang 25127, West Sumatra, Indonesia ${ }^{4}$

\begin{abstract}
Carcinoma of mammae is a basis of the greatest ferocity that was discovered in of women in the project in an advanced state of and developing countries. Many a gene that has reportedly exchanged in carcinogenesis carcinoma mammae as PTEN, IGFR, Ki67, Her-2 neu, and p53 are classified as a factor prognostic. It is still a little research report about the expression of PTEN and expression IGFR in the case carcinoma mammae invasive especially in Indonesia. The purpose of this study is to know the relationship between expression PTEN and expression IGFR with Ki-67 expression and grade histopatology of carcinoma mammae invasive. This study took data from Center Diagnostic Anatomical Pathology Department of Medical Faculty, Andalas University, West Sumatera, Indonesia, the period of 1 January 2014 to 31 December 2015. The expression of by immunohistochemistry (IHC) PTEN, IGFR and Ki-67 antibodies in paraffin block from 55 cases of carcinoma mammae invasive diagnosed. PTEN and IGFR positive expression were mostly found in grade II carcinoma mammae invasive compared to grade III. Expression Ki-67 $\geq 14 \%$ more found on the expression of PTEN and IGFR positive. There was no significant correlation between PTEN expression with grading histopathology and expression of $\mathrm{Ki}-67$; the same there was no significant correlation between IGFR expression with grading histopathology and expression of Ki-67.
\end{abstract}

Keywords: Carcinoma Mammae Invasive- PTEN- IGFR- Ki-67- Grading Histopathology.

\section{Introduction}

Carcinoma of mammae on women share the main health problems of all over the world. Carcinoma of mammae is a basis of the greatest ferocity that was discovered in of women in the project in an advanced state of and developing countries [1]. Ductal carcinoma invasive is the type of cancer that found approximately 70-80 \%.In 2010, more than 200.000 ductal carcinoma invasive in women diagnosed in the United States. About 40,000 women died of this disease and is the second cause of death after lung cancer in women [2]. Based on the data Global Cancer International Agency for Research on Cancer (GLOBOCAN IARC) in 2012, the number of cases new carcinoma mammae in the world estimated at 1.67 million cases of or 43 cases per 100,000 population. The incident carcinoma mammae most found to developed countries in western such as the United States and Europe [1],[3]. 
In Indonesia, the data from Registration Agency Cancer The Association of Specialized Doctors Pathology of Indonesia have reported that carcinoma of mammae is a subsidiary the members of primary ferocity with the highest proportion in Indonesia in 2013 by the number of cases diagnosed as many as 6324 cases $21,02 \%$. The same data also reported that carcinoma mammae are most ferocity primary diagnosed West Sumatera by the number of cases as many as 473 cases ( $29,29 \%$ ) [4].

Carcinoma mamae having biologic behavior very heterogeneous, so it takes many parameters to the determination of prognosis and therapeutic accurate. In the research, many a gene that has reportedly exchanged in carcinogenesis carcinoma mammae as PTEN, IGFR, Ki67, Her-2 neu, and p53 are classified a factor prognostic [2].

Phosphatase and tensin homolog (pten) is genes suppressor tumor located on a chromosome 10q23. A mutation PTEN going on to a variety of tumor. Mutation germline PTEN associated with hamartoma autosomal dominant and syndrome often accompanied by cancer. Meanwhile, inactivation PTEN homozygous has been found on some cancer sporadic. The reduction and loss of expression PTEN primary tumor proteins found in the frequency of about $20 \%$ in gastric carcinoma to nearly $70 \%$ to the Non-Small Cell Lung Carcinoma (NSCLC) [5,6].

Insulin-Like Growth Factor (IGFR) is a system consisting of IGF-1, IGF-binding proteins (IGFBPs) and IGF-1 Receptor (IGF-1R) play an important role in the physiology of human beings, especially it was reflected from a variety of poverty eradication a network of including a gland mamae.IGF-1R is a signal trigger in early proliferation and anti-apoptosis [7].

Insulin-Like Growth Factor has a role in the proliferation of important in regulating, differentiation, cell apoptosis, and transformation. Insulin-like growth factor shows it works through interaction with a specific receptor into the cell membrane which is called by $I G F-I$ receptor (IGF-IR). The interaction between IGF with IGF-IR is regulated by a group of protein binding a specific protein. All molecules are known to as a member of the family IGF namely ( i ) polypeptide ligands IGF-I R and IGF-II R, ( ii ) two types of receptors cell membranes namely IGF-I R and IGF-II R and ( iii ) six protein binding namely IGFBP-1 until IGFBP-6 [8].

So far is still a little research report about the expression of PTEN and expression IGFR in the case carcinoma mammae invasive especially in Indonesia. This knowledge is important to recognize and get the prognosis for carcinoma of mamae invasive cases in Indonesia. Hence this research designed to know the relationship between expression PTEN and expression IGFR with Ki-67 expression and grade histopathology of carcinoma mammae invasive.

\section{Materials and Methods}

\subsection{Sampling Preparation}

The design of this study was a cross-sectional study. Subject used in this study were 55 paraffinembedded tissues of invasive carcinoma mammae in 2014-2015 from the Center Diagnostic Anatomical Pathology Department of Medical Faculty, Andalas University, West Sumatera, Indonesia. Clinical and histopathologic information was retrieved from the medical record. The study was approved by the Research Ethics Committee of Faculty of Medicine, Andalas University. Samples that are contain small focus of tumor were excluded from this study. Hematoxylin Eosin (HE) slides were examined to classify cancer morphology into I, II and III grade tumor based on WHO Criteria [9]. 


\subsection{Immunohistochemically Analysis}

Samples were stained immunohistochemically using monoclonal antibody anti-PTEN (Abcam, EPR 9941-2, dilution 1: 50), polyclonal antibody anti IGFR (Bioss, bs-0227r, dilution 1: 100) and Ki-67 (Abcam ab 16667, dilution 1:100). DAB chromogen and counter stain Hematoxyllin Mayer were used in this study. Expression of PTEN, IGFR, and Ki-67 were determined under light microscopy by two independent observers. Samples are considered PTEN positive if intensity with distribution diffuse, regional, focal or moderate with distribution diffuse. Diffuse if $>50 \%$ of tumor cells show positive nuclear staining, regional if $15-50 \%$ of tumor cells show positive nuclear staining, focal if $<50 \%$ of tumor cells show positive nuclear staining). ${ }^{[10]}$ Samples are considered IGFR positive if $\geq 10 \%$ of tumor cells show positive membrane staining with weak-moderate intensity (Score 2 ) or $\geq 10 \%$ of tumor cells show positive membrane staining with strong intensity (Score 3) [11]. Ki-67 expression is considered high if $\geq 14 \%$ of tumor cells show positive nuclear staining [12].

\subsection{Statistical analysis}

Bivariate analysis was used to identify the correlation between (PTEN and IGFR expression) with (Ki-67 expression and Grade of Histopathologic Carcinoma Mammae Invasive). Correlation between (PTEN and IGFR expression) with (Ki-67 expression and Grade of Histopathologic Carcinoma Mammae Invasive) was analyzed using Chi-square with significance when the $\mathrm{p}$-value was $<0.05$. Statistical analysis was performed using the SPSS version 9.0 software program.

\section{Result}

Demographic and clinical characteristics of this study (Table 1) demonstrated that most of patients age were 50-59 year $(32,7 \%)$, the proportion of postmenopausal patients was $59.3 \%$, and most of the grade of histopathologic was grade $2(80,0 \%)$.

Table 1. Demographic and Clinical Characteristic Carcinoma Mammae Invasive

\begin{tabular}{lll}
\hline Characteristics & $\mathbf{f}(\mathbf{n}=\mathbf{5 5})$ & \% \\
\hline Age & & \\
$<30$ & 3 & 5,5 \\
$30-39$ & 9 & 16,4 \\
$40-49$ & 15 & 27,3 \\
$50-59$ & 18 & 32,7 \\
$>59$ & 10 & 18,2 \\
\hline Grading & 1 & 1,8 \\
Grade I & 44 & 80,0 \\
Grade II & 10 & 18,2 \\
Grade III & & \\
\hline
\end{tabular}

Carcinoma mammae invasive grade II more found on the expression of PTEN positive $(82,6$ $\%$ ) than expression PTEN negative $(78.1 \%$ ). Carcinoma mammae invasive grade III more found on the expression of PTEN negative $(21,9 \%)$ than expression PTEN positive $(13,0 \%)$ (Table 2). Statistically, the results of the Mann-Whitney test the range of the value of $p=0,269$ means 
that there was no significant correlation between expression of PTEN with grading histopathologic of carcinoma mammae invasive.

Table 2. Expression of PTEN with grading histopathology of carcinoma mammae invasive.

\begin{tabular}{|c|c|c|c|c|c|c|c|c|c|}
\hline \multirow{2}{*}{$\begin{array}{c}\text { PTEN } \\
\text { expression }\end{array}$} & \multicolumn{6}{|c|}{ Grading histopathologic } & \multirow{2}{*}{\multicolumn{2}{|c|}{ Total }} & \multirow{2}{*}{$p$-value } \\
\hline & I & & II & & II & & & & \\
\hline & $f$ & $\%$ & $f$ & $\%$ & $\mathrm{f}$ & $\%$ & $\mathrm{f}$ & $\%$ & \\
\hline Negative & 0 & 0 & 25 & 78,1 & 7 & 21,9 & 32 & 100 & 0,269 \\
\hline Positive & 1 & 4,3 & 19 & 82,6 & 3 & 13,0 & 23 & 100 & \\
\hline
\end{tabular}

Expression Ki-67 $\geq 14 \%$ is more found on the expression of PTEN positive $(69,6 \%)$ than expression PTEN negative $(65.6 \%)$ (Table 3). Statistically, the results of the chi-square test the range of the value of $p=0,987$ mean that there was no significant correlation between expression PTEN with expression Ki-67.

Table 3. Expression PTEN with expression Ki-67.

\begin{tabular}{|c|c|c|c|c|c|c|c|}
\hline \multirow{3}{*}{$\begin{array}{l}\text { Expression } \\
\text { PTEN }\end{array}$} & \multicolumn{4}{|c|}{ Expression Ki-67 } & \multirow{2}{*}{\multicolumn{2}{|c|}{ Total }} & \multirow{3}{*}{$p$-value } \\
\hline & \multicolumn{2}{|c|}{$<14 \%$} & \multicolumn{2}{|c|}{$\geq 14 \%$} & & & \\
\hline & $\mathrm{f}$ & $\%$ & $\mathrm{f}$ & $\%$ & $\mathrm{f}$ & $\%$ & \\
\hline Negative & 11 & 34,4 & 21 & 65,6 & 32 & 100 & \\
\hline Positive & 7 & 30,4 & 16 & 69,6 & 23 & 100 & 0,987 \\
\hline
\end{tabular}

Carcinoma mammae invasive grade II more found on the expression of IGFR positive $(80,6$ $\%$ ) than expression IGFR negative $(79,2 \%)$. Carcinoma mammae invasive grade III more found on the expression of IGFR negative $(20,8 \%)$ than expression IGFR positive $(16,1 \%)$ (Table 4$)$. Statistically, the results of the Mann-Whitney test the range of the value of $p=0,509$ means that there was no significant correlation between expression of IGFR with grading histopathologic of carcinoma mammae invasive.

Table 4. Expression of PTEN with grading histopathology of carcinoma mammae invasive.

\begin{tabular}{|c|c|c|c|c|c|c|c|c|c|}
\hline \multirow{2}{*}{$\begin{array}{l}\text { Expression } \\
\text { IGFR }\end{array}$} & \multicolumn{6}{|c|}{ Grading histopathologic } & \multirow{2}{*}{\multicolumn{2}{|c|}{ Total }} & \multirow{2}{*}{$p$-value } \\
\hline & I & & II & & III & & & & \\
\hline & $\mathrm{f}$ & $\%$ & $\mathrm{f}$ & $\%$ & $\mathrm{f}$ & $\%$ & $\mathrm{f}$ & $\%$ & \\
\hline Negative & 0 & 0 & 19 & 79,2 & 5 & 20,8 & 32 & 100 & 0,509 \\
\hline Positive & 1 & 3,2 & 25 & 80,6 & 5 & 16,1 & 23 & 100 & \\
\hline
\end{tabular}

Expression Ki-67 $\geq 14 \%$ is more found on the expression of IGFR positive $(74,2 \%)$ than expression IGFR negative $(58,3 \%)$ (Table 5). Statistically, the results of the chi-square test the range of the value of $p=0,340$ mean that there was no significant correlation between expression IGFR with expression Ki-67.

Table 5. Expression IGFR with expression Ki-67. 


\begin{tabular}{|c|c|c|c|c|c|c|c|}
\hline \multirow{3}{*}{$\begin{array}{l}\text { Expression } \\
\text { IGFR }\end{array}$} & \multicolumn{4}{|c|}{ Expression Ki-67 } & \multirow{3}{*}{\multicolumn{2}{|c|}{$\begin{array}{c}\text { Total } \\
\%\end{array}$}} & \multirow[t]{3}{*}{$p$-value } \\
\hline & \multicolumn{2}{|c|}{$<14 \%$} & \multicolumn{2}{|c|}{$\geq 14 \%$} & & & \\
\hline & $\mathrm{f}$ & $\%$ & $\mathrm{f}$ & $\%$ & & & \\
\hline Negative & 10 & 41,7 & 14 & 58,3 & 24 & 100 & \\
\hline Positive & 8 & 25,8 & 23 & 74,2 & 31 & 100 & 0,340 \\
\hline
\end{tabular}

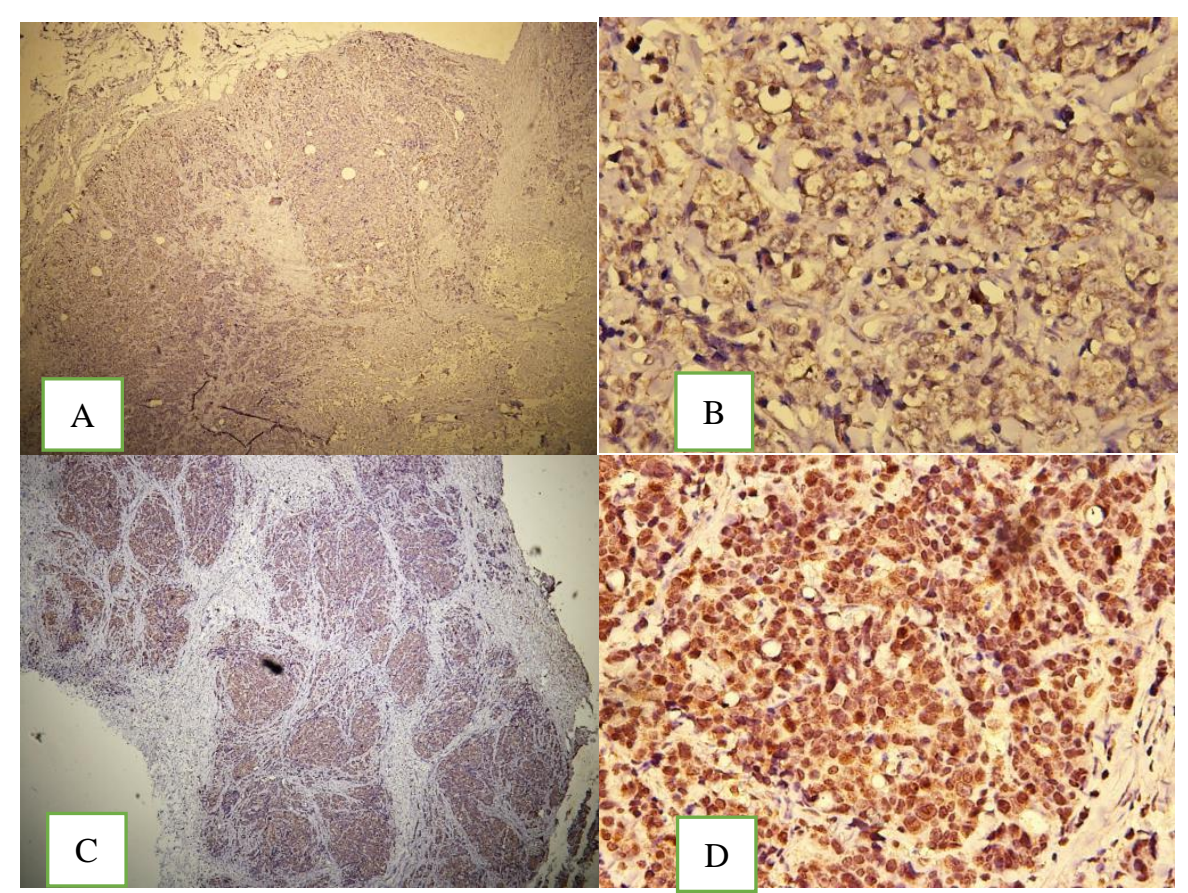

Fig. 1. (A,B). Expression of PTEN in carcinoma mammae invasive with expression PTEN negative (C,D). Expression of PTEN in carcinoma mammae invasive with expression PTEN positive.

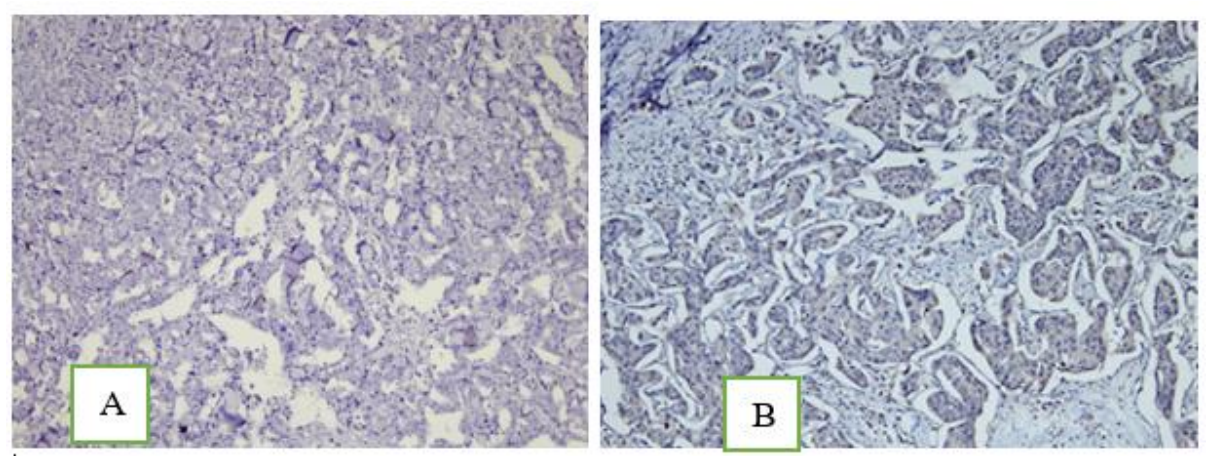

Fig. 2. (A). Expression of IGFR in carcinoma mammae invasive with expression IGFR negative (B). Expression of IGFR in carcinoma mammae invasive with expression IGFR low. 


\section{Discussion}

This Present study found that most carcinoma mammae invasive found at age group 50-59 years as many as $32,7 \%$. Different from the data that carcinoma mammae happened at the age of the younger in Asian countries. The mean of the patient's age of carcinoma mammae is 50 years with the most age group between 40-49. It is also different from any Western state where age group carcinoma mammae patients with the highest proportion are between the ages of 6070 years. More than $50 \%$ of patients carcinoma mammae in Asia younger than 50 years and more than $60 \%$ is premenopause $[13,14]$.

In this study grade, I carcinoma mammae invasive was found $1,8 \%$; grade II was found $80,0 \%$, and grade III was found $18,2 \%$. High-grade tumor correlation with the nature tumor aggressive and worse prognosis grading histopathology including minor prognostic factors and predictive factors which assessed in predict the therapy. The higher grade of differentiation tumor, the worse prognosis [15].

In this study showed the results of positive on staining immunohistochemistry PTEN about $4,3 \%$ at grade I, $82,6 \%$ at grade II and $13 \%$ at grade III. Statistical analysis uses the MannWhitney test there was no significant correlation between expression PTEN with grade histopathology carcinoma mamae invasive. This is consistent with found Zhang et al. that expression PTEN shows no significant correlation with grade histopathology carcinoma mamae invasive.[16] From this study also expression Ki-67 $\geq 14 \%$ more found on the expression of PTEN positive $(69,6 \%)$. This is in accordance with research lin et al. that expression Ki-67 $\geq$ $14 \%$ more found on the expression of PTEN positive. Chi-square test showed that there was no significant correlation between PTEN expression with the expression of Ki-67.

Based on the results of investigation immunohistochemistry IGFR in this study showed grade II more found on the expression of IGFR positive $(80,6 \%)$. This is in accordance with finding Su-ji shin et al. that IGFR positive most found in grade II.[17] From this study also obtained expression Ki-67 $\geq 14 \%$ more found on the expression of IGFR positive $(74,2 \%)$ than expression IGFR negative $(58,3 \%)$. Statistical analysis with Mann-Whitney test showed that there was no significant correlation between expression IGFR with grade histopathology of carcinoma mammae invasive.

Chi-square test showed there was no significant correlation between IGFR expression with the expression of $\mathrm{Ki}-67$. In line with research conducted by sun et al. that there was no significant correlation between IGFR expression with grade histopathology of carcinoma mammae invasive and IGFR expression with expression of Ki-67.[18]

There is a shortage of experimental work on this and weakness that can affect the results of PTEN, IGFR and Ki-67 expression. First, is the technical factor which the techniques that used is partly done manually and the use of a machine did others.

The results of staining immunohistochemistry are less than perfect. Wrong fixation or processing tissues could cause this. A problem with fixation is the type fixation used, delay in fixation tissues and excessive fixation. Solution fixation advocated is solution formalin $10 \%$ a buffer, while solution a fixative that is used in some samples has still not been standardized. Time fixation at least eight hours and a maximum of 48 hours. Besides, the good quality of block paraffin also influence to immunohistochemistry staining results

Second, an unequal the distribution of a sample carcinoma mammae invasive grade I the number was very small compared with carcinoma mammae invasive with grade II and III, it is a great deal can influence the results of the statistical tests. 


\section{Conclusion}

In this study there was no significant correlation between PTEN expression with grading histopathology and expression of Ki-67; the same there was no significant correlation between IGFR expression with grading histopathology and expression of Ki-67.

Acknowledgments. This research was supported by PNBP grant 2016, from Faculty of Medicine, Andalas University, West Sumatera, Indonesia.

\section{References}

[1] Ferlay J, He'ry C, Autier P, Sankaranarayanan R.: Global Burden of Breast Cancer. In (Li CI, ed) Breast Cancer Epidemiology. New York: Springer Science + Business Media, pp. 1-19 (2010)

[2] Kumar, Abbas, Aster.: Pathologic Basis of Disease .9 ${ }^{\text {th }}$ ed. Chapter 23. The Breast, pp.1043-50 (2014)

[3] American Cancer Society.: Breast Cancer Facts and Figures 2017 - 2018. Atlanta: American Cancer Society, pp. 1-28 (2017)

[4] Badan Registrasi Kanker Perhimpunan Dokter Spesialis Patologi Indonesia, 2013.: Kanker di Indonesia Tahun 2013: Data Histopatologik. Jakarta: Yayasan Kanker Indonesia (2013).

[5] Panagiotou I, Georgiannos SN, Tsiambas E, Karameris A, Konstantinou M, Lazaris AC.: Impact of HER2 and PTEN Simultaneous Deregulation in Non-small Cell Lung Carcinoma: Correlation with Biological Behavior. Asian Pacific J Cancer Prev, Vol. 13, No. 12, pp. 6311-18 (2012).

[6] Ebbesen SH, Scaltriti M, Bialucha CU, Morse N, Kastenhuber ER, Wen HY.:Pten loss promotes MAPK pathway dependency in HER2/neu breast carcinomas. PNAS, Vol. 113, No. 11, pp. 3030-35. www.pnas.org/lookup/suppl/doi:10.1073_(2016)

[7] Christopoulus, Msaunee, Kontsikeris.: The Role of The Insulin-like Growth Factor-1 System In Breast Cancer. 14:43. www.ncbi.com (2015)

[8] Yu H, Rohan T.: Role of the Insulin-Like Growth Factor Family in Cancer Development and Progression. Journal of the National Cancer Institute, Vol. 92, No. 18, pp. 1472-89 (2000)

[9] Lakhani SR, Reis-Filho JS, van de Vijver MJ.: Molecular Pathology Overview Invasive Breast Carcinoma. In (Lakhani SR, Ellis IO, Schnitt SJ, Tan PH, van de Vijver MJ, eds) WHO Classification of Tumours of The Breast, $4^{\text {th }}$ ed. Lyon: International Agency for Research on Cancer, pp. 28 (2012)

[10] Kechagioglou P, Rapi RM, Provatopoulou X, Kalogera E, Papadimitriou E, Grigoropoulus P et al.: Tumor Supressor PTEN in Breast Cancer: Heterozygosity, Mutations and Protein Expresion . J Anti Cancer Research, vol 34, pp 1387-1400 (2014)

[11] Aaltonen KE, Rosendahl AH, Olsson H, Malmström P, Hartman L, Fernö M.: Association between insulin-like growth factor-1 receptor (IGF1R) negativity and poor prognosis in a cohort of women with primary breast cancer. BMC cancer, Vol. 14, No. 794, pp.1-13 (2014)

[12] Inwald, Schalke, Hofstadter, Zeman, Koller, Gerstenhauer et al.: Ki-67 is a Prognostic Parameter in Breast Cancer Patients: Results of Large Population-Based Cohort of A Cancer Registry. Breast Cancer Res Treat. Vol 139.pp 539-552 (2013)

[13] Yip CH.:. Breast Cancer in Asia. Methods in Molecular Biology, Vol. 471, pp. 51-64 (2009)

[14] Curado MP.: Breast Cancer in The World: Incidence and Mortality. Salud Publica Mex,Vol. 53, No. 5, pp. 372-84 (2011)

[15] Hutagalung, Mulyadi, Artha.: Ekspresi Ki-67 dan HER-2/neu Berhubungan dengan Derajat Histopatologik Karsinoma Payudara Invasif No Special Type,Vol.23, No.2,pp 45-48 (2014)

[16] Zhang, Liang, Jia, Song, Jiang.: PTEN mutation, methylation and expression in breast cancer patients. Oncology letters 6, pp.161-168 (2013) 
[17] Su-Ji Shin, Gong, Lee, Kang, Bae, Lee A, Cho et al.: Positif Expression of Insulin Like Growth Factor-1 Receptor Is Associated with a Positive Hormone Receptor Status and A Favorable Prognosis In Breast Cancer. J.Breast Cancer, Vol. 17, No.2.pp113-26 (2014)

[18] Sun, Yun, Song, Kim, Lee, Nam et al.: Insulin-like Growth Factor 1 Receptor Expression In Breast Cancer Tissue and Mammographic Density. Molecular and Clinical Oncology, Vol.3, pp.572-80 (2015) 